deprivation. After $10 \mathrm{~min}$, there is still no change. The results for the 30 -min tests show the expected increase in percentage intake (although only marginally significant) for the 24-h group. This rise was somewhat understated because the 30-min test data included preselection sampling. Therefore, we subtracted the 10 -min intakes from the $30-\mathrm{min}$ intakes in order to obtain an estimate of 10- to 30 -min intakes. The results are given as Xs in Fig. 1.

The primary purpose of this experiment was to show that the increased intake ratios found previously (Gentile \& Hoff, 1970 ) in a $30-\mathrm{min}$ test were an artifact of postselection intake. This suggestion was confirmed, for the concentration of quinine used, by the results of the 5- and 10-min preference tests.

In summary, there is no good evidence for change in the importance of taste in preference as a function of food deprivation since the apparent changes found in the 30-min test do not show up in 5- and 10-min tests. The changes that do occur in the $30-\mathrm{min}$ test are confined primarily to the 24-h condition. By virtue of the fact that total intake for this condition is greater than for either of the others, it would be expected that postselection eating would be greatest for this group; it may even be that the 24-h group is the only one that eats enough to be able to make a selection in the time allowed. Thus, this change is not inconsistent with the general position that the importance of taste is not affected by length of food deprivation.

The possibility remains (we believe it is remote) that these results apply only to the particular pair of diets tested in the 5- and 10 -min tests, that the magnitude of the selection effect is not sufficiently large to account completely for the somewhat larger differences across deprivation conditions found for the other three diets tested in our previous study (Gentile \& Hoff, 1970). One may also be disturbed by the failure of the 4- and 8-h groups to show any signs of selection during the 10 - to 30 -min period. We believe that a certain amount of intake is necessary before a choice can be made and that these groups do not achieve the amount required for this choice. It is also possible, however, that there are other differences in eating style (rate, method of sampling, etc.) among groups that could equally well account for the observed differences in selection.

A proper summary for this article and the two preceding (Hoff \& Gentile, 1969; Gentile \& Hoff, 1970) would be the following: Attempts to ascertain possible modulation of the role of taste in food intake and food preference as a function of deprivation are faced with many inherent difficulties. The major problem is defining what one means by such changes. Included in this are the problems of establishing criteria for change and of knowing how to interpret the data one obtains in terms of the behavior of the animal. Our own conclusion that the role of taste is not changed is based primarily on our cumulative failure, in tests we consider fair to both predictions, to find logically convincing evidence for change in either direction

\section{REFERENCES}

CAMPBELL, B. A. Absolute and relative sucrose preference thresholds for hungry and satiated rats. Journal of Comparative \& Physiological Psychology, 1958, 57, 795-800.

EPSTEIN, A. N. Oropharyngeal factors in feeding and drinking. In C. F. Code and W. Heidel (Eds.), Handbook of physiology, Section 6: Alimentary canal. Vol. I. Washington, D.C: American Physiological Society, 1967. Pp. 197-218.
GENTILE, R. L., \& L. A. HOFF, Does food deprivation affect the role of taste in a two-choice preference test?: 1. Psychonomic Science, 1970, 19, 297-298.

HOFF, L. A., \& R. L. GENTILE. Deprivation and the role of taste in food intake. Psychonomic Science, 1969, 17, 277-278.

JACOBS, H. L. Sensory and metabolic regulation of food intake: Thoughts on a dual system regulated by energy balance. In: Proceedings of the Seventh International Congress of Nutrition, Hamburg, 1966. Vol. II. Regulation of hunger and satiety. Oxford: Pergamon, 1967. Pp. 17-29.

\section{NOTES}

1. This research was carried out at the Pioneering Research Laboratory, Behavioral Sciences Division, U.S. Army Natick Laboratories, Natick, Mass. 01760.

2. USPHS Post-Doctoral Fellow, Department of Biology, Clark University. Corresponding address: see Note 1

3. Now at Psychology Department, University of Georgia, Athens, $\mathrm{Ga} .30601$.

4. Fisher Scientific Co. (NF).

5. We would like to thank Dr. Harry L. Jacobs for his suggestions and constructive criticisms.

\title{
Familiarity of target location as a factor in the shock-associated aggression of wild rats ${ }^{1}$
}

\author{
BENNETT G. GALEF, JR., McMaster \\ University, Hamilton, Ontario, Canada
}

In response to moderate foot shock, wild rats exhibit markedly more aggression toward a familiar inanimate target stimulus placed in a new location than toward the same target in its familiar location. The results are discussed in terms of the relationship between aggressive and avoidance behaviors in wild rats.

Wild rats exhibit a marked tendency to avoid an unfamiliar object introduced into familiar surroundings (Barnett, 1958,
1963; Chitty \& Shorten, 1946). They also tend, to a lesser extent, to avoid familiar objects placed in new locations within a known environment (Barnett, 1958, 1963; Calhoun, 1962). Thus, the so-called "new object reaction [Shorten, 1954]," or "neophobic" avoidance response of the wild rat (Barnett, 1958) is elicited by two distinct kinds of alteration in a previously explored, and therefore familiar, environment.

In a recent paper (Galef, 1970), evidence was presented suggesting that the novelty avoidance and aggressive behaviors of wild rats were two manifestations of the 
wild rat's response to novelty in that both serve similar functions in the life of the animal (Scott \& Fredericson, 1951); both are released or elicited by the introduction of a novel object into the environment and both depend on the intact functioning of the amygdala for their occurrence. In a subsequent paper (Galef, in press) it was shown that the introductior. of an unfamiliar inanimate object into the home cage of a wild rat markedly increased the frequency of occurrence of aggressive behavior in response to moderately intense foot shock. Thus, one of the two types of alteration in a familiar environment known to elicit avoidance behavior in the wild rat was also demonstrated to be effective in eliciting aggression in response to painful stimulation. If avoidance behavior and aggression in the wild rat are two varieties of response to novelty, then it would be expected that the second type of alteration in a familiar environment known to result in avoidance (change in the position of a familiar object) would similarly increase the frequency of occurrence of aggressive behavior in response to painful stimulation.

\section{SUBJECTS}

The Ss were 16 experimentally naive adult first-generation laboratory-bred wild rats, the offspring of feral animals captured on a farm in Maine. Data from one $S$ was discarded because it climbed onto one of the target stimuli and thus avoided shock. APPARATUS

Four large shock boxes (12 $\times 15 \times 24$ in.) were constructed using black opaque Plexiglas for three walls and transparent Plexiglas for the front wall. The top of each box was closed with a plate of opaque white Plexiglas in which two holes, 11/4 in. in diam, were drilled 2 in. from the back wall of the shock box and $10 \mathrm{in}$. apart, to permit lowering of stimuli into the enclosure. The grid floor of the box was constructed of stainless steel rods of 3/16 in. diam, 5/16 in. apart, and shocks were administered via a Grason-Stadler Model E1064GS shock generator and scrambler controlled by relay equipment. Water and powdered Purina Rat Chow were available ad lib, the latter from an externally mounted Norwich NS feeder.

Targets were $1 \frac{11}{4}$-in.-diam hardwood balls mounted on aluminum poles $3 / 8$ in. in diam and $24 \mathrm{in.} \mathrm{long.} \mathrm{The} \mathrm{targets} \mathrm{were}$ painted white, and one target was mounted to the lid of each shock box by means of a clamp. These targets could be lowered into or removed from the cage by the $\mathrm{E}$ through the holes in the lid of the enclosure.

\section{PROCEDURE}

The Ss were divided randomly into experimental (eight Ss) and control (seven Ss) groups. Both groups were treated identically for the firs! 14 days of the experiment. On Day 1 individual Ss were placed in each shock box and the target stimulus lowered to within 4 in. of the grid floor. Ss were then left undisturbed for 13 days to become accustomed to the shock box and the target. On Day 14, the target was removed from the shock box and immediately returned to its original position. The $\mathrm{E}$ waited $5 \mathrm{~min}$ following reintroduction of the target stimulus and then delivered five shocks of 1.0-sec duration and $1.3-\mathrm{mA}$ intensity at intervals of $60 \mathrm{sec}$. On Day 15, the target stimulus was removed from the cage of each $S$ in the experimental group and immediately reintroduced into the enclosure through the other aperture in the lid of the experimental box and lowered to its original level. The target stimulus was thus displaced 10 in. laterally from its familiar position in the shock box of each experimental S. Five minutes following reintroduction of the target into each experimental rat's enclosure the $E$ delivered five shocks $(1.3 \mathrm{~mA}, 1.0 \mathrm{sec})$ to each experimental S, as on Day 14. The Ss in the control group were treated in the same fashion on Day 15 as they had been on Day 14; that is, the target stimulus was removed from each control S's enclosure and immediately returned to its original location. The $\mathrm{E}$ then waited $5 \mathrm{~min}$ and delivered five shocks of $1.3-\mathrm{mA}$ intensity and $1.0-\mathrm{sec}$ duration. Thus, the control and experimental groups were treated identically except on Day 15 when the position of the familiar target stimulus was altered in the cages of experimental, but not control, Ss.

The $E$ recorded the number of attacks delivered to the target stimulus by each $S$ during each 60-sec postshock interval on Days 14 and 15. An attack was recorded whenever a $S$ approached and bit a target. The duration of biting attacks and the number of discriminable bites comprising an attack episode appeared to vary considerably; however, simple observation did not permit accurate quantification of attack durations or number of bites. The $\mathrm{E}$ simply recorded a separate attack whenever a $\mathbf{S}$ disengaged from and then returned to bite its target.

\section{RESULTS}

The results of the experiment are presented in Table 1. On Day 15, when the target was moved from its original location to one $10 \mathrm{in}$. distant in the cages of the experimental Ss, these animals showed a considerable increase in both mean number of attacks and proportion of shock trials on which aggression occurred over baseline levels on Day 14. The control animals, by comparison, showed no change in incidence of aggression between the 2 days of the experiment on either measure. All
Table 1

Mean Number of Attacks and Proportion of Trials on Which Attacks Were Observed in Response to Shock

\begin{tabular}{cccccc}
\hline & \multicolumn{2}{c}{ Experimental } & & \multicolumn{2}{c}{ Control } \\
\cline { 2 - 3 } \cline { 5 - 6 } Day & $\begin{array}{c}\text { Attacks } \\
\mathrm{N}=8\end{array}$ & $\begin{array}{c}\text { Trials } \\
\mathrm{N}=40\end{array}$ & $\begin{array}{c}\text { Attacks } \\
\mathrm{N}=7\end{array}$ & $\begin{array}{c}\text { Trials } \\
\mathrm{N}=35\end{array}$ \\
\hline 14 & .43 & .05 & .71 & .12 \\
15 & 3.5 & .40 & .57 & .11 \\
\hline
\end{tabular}

eight experimental Ss showed increased aggression on both measures on Day 15 as compared with Day 14, while only one of the seven control Ss showed an increase in either measure, and two of seven controls showed a decrease in aggression on both measures.

\section{DISCUSSION}

The implications of the results of the present experiment are twofold. First, the results indicate that the type of novel stimulation eliciting aggressive behavior is broader than previously conceived (Galef, 1970). Both the introduction of an unfamiliar stimulus into a familiar environment (Galef, in press) and the change in position of a known stimulus result in enhanced aggression. Second, the present finding provides support for the hypothesis that aggression and avoidance behaviors in the wild rat may be two manifestations of some single underlying process elicited by novel stimulation, in that this second type of manipulation in a familiar environment which produces heightened aggression is also a manipulation that has been shown to result in avoidance.

BARNETT, S. A. Experiments on 'neophobia' in wild and laboratory rats. British Journal of Psychology, 1958, 49, 195-201.

BARNETT, S. A. The rat: $A$ study in behavior. Chicago: Aldine, 1963.

CALHOUN, J. B. The ecology and sociology of the Norway rat. U.S. Department of Health, Education, and Welfare, Bethesda. Md.. 1962.

CHITTY, D., \& SHORTEN, M. Techniques for the study of the Norway rat (Rattus norvegicus). Journal of Mammalogy, 1946, 27 , 63-78.

GALEF, B. G., JR. Aggression and timidity Responses to novelty in feral Norway rats. Journal of Comparative \& Physiological Psychology, 1970, 70, 370-381.

GALEF, B G., JR. Target novelty elicits and directs shock-associated aggression in wild rats. Journal of Comparative \& Physiological Psychology, in press.

SCOTT, J. P., \& FREDERICSON, E. The causes of fighting in mice and rats. Physiological Zoology, 1951, 24, 273-309.

SHORTEN, M. The reaction of the brown rat towards changes in its environment. In D. Chitty (Ed.), The control of rats and mice. Vol. II. London: Oxford Press, 1954. Pp. 307-333.

\section{NOTE}

1. This research was supported by Grant APA 0307 of the National Research Council of Canada. 